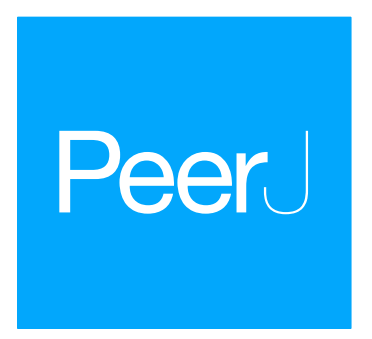

Submitted 15 January 2016 Accepted 2 July 2016 Published 23 August 2016

Corresponding author Wu Dong,wu.dong@duke.edu

Academic editor John Stegeman

Additional Information and Declarations can be found on page 11

DOI 10.7717/peerj.2282

Copyright

2016 Dong et al.

Distributed under

Creative Commons CC-BY 4.0

OPEN ACCESS

\section{Developmental toxicity from exposure to various forms of mercury compounds in medaka fish (Oryzias latipes) embryos}

\author{
Wu Dong ${ }^{1,2}$, Jie Liu ${ }^{3}$, Lixin Wei ${ }^{4}$, Yang Jingfeng ${ }^{1}$, Melissa Chernick ${ }^{2}$ and \\ David E. Hinton ${ }^{2}$ \\ ${ }^{1}$ Inner Mongolia Provincial Key Laboratory for Toxicants and Animal Disease, College of Animal Science and \\ Technology, Inner Mongolia University for the Nationalities, Tongliao, China \\ ${ }^{2}$ Nicholas School of the Environment, Duke University, Durham, NC, United States \\ ${ }^{3}$ Zunyi Medical College, Department of Pharmacology, Zunyi, China \\ ${ }^{4}$ Department of Tibetan Medicine, Northwest Institute of Plateau Biology, Chinese Academy of Sciences, \\ Xining, China
}

\section{ABSTRACT}

This study examined developmental toxicity of different mercury compounds, including some used in traditional medicines. Medaka (Oryzias latipes) embryos were exposed to 0.001-10 $\mu \mathrm{M}$ concentrations of $\mathrm{MeHg}, \mathrm{HgCl} 2, \alpha-\mathrm{HgS}$ (Zhu Sha), and $\beta$ $\mathrm{HgS}$ (Zuotai) from stage 10 (6-7 hpf) to 10 days post fertilization (dpf). Of the forms of mercury in this study, the organic form $(\mathrm{MeHg})$ proved the most toxic followed by inorganic mercury $\left(\mathrm{HgCl}_{2}\right)$, both producing embryo developmental toxicity. Altered phenotypes included pericardial edema with elongated or tube heart, reduction of eye pigmentation, and failure of swim bladder inflation. Both $\alpha-\mathrm{HgS}$ and $\beta-\mathrm{HgS}$ were less toxic than $\mathrm{MeHg}$ and $\mathrm{HgCl}_{2}$. Total RNA was extracted from survivors three days after exposure to $\mathrm{MeHg}(0.1 \mu \mathrm{M}), \mathrm{HgCl}_{2}(1 \mu \mathrm{M}), \alpha$-HgS $(10 \mu \mathrm{M})$, or $\beta$-HgS $(10 \mu \mathrm{M})$ to examine toxicity-related gene expression. $\mathrm{MeHg}$ and $\mathrm{HgCl}_{2}$ markedly induced metallothionein (MT) and heme oxygenase-1 (Ho-1), while $\alpha$-HgS and $\beta$-HgS failed to induce either gene. Chemical forms of mercury compounds proved to be a major determinant in their developmental toxicity.

Subjects Aquaculture, Fisheries and Fish Science, Developmental Biology, Toxicology, Pharmacology, Public Health

Keywords MeHg, HgCl2, $\alpha$-HgS (Zhu Sha, cinnabar), $\beta$-HgS (Zuotai), Medaka, Developmental toxicity, Heme oxygenase-1, Mercury, Metallothionein

\section{INTRODUCTION}

Mercury-based traditional medicines are an important consideration in public health of specific countries. For centuries, mercury has been used as an ingredient in diuretics, antiseptics, skin ointments and laxatives, and more recently, as a dental amalgam and as a preservative in some vaccines (Clarkson, Magos \& Myers, 2003; Liu et al., 2008). In traditional Indian Ayurvedic (Kamath et al., 2012), Chinese (Pharmacopeia of China, 2015) and Tibetan medicines (Chen et al., 2012; Kan, 2013; Li et al., 2014; Wu et al., 2016), mercuric sulfides are frequently included in the treatment of various disorders, with the result that health concerns for public safety are increasing (Liu et al., 2008; Kamath et al., 2012). This form of mercury, from the naturally occurring minerals, cinnabar and 
metacinnabar, typically undergoes purification and preparation prior to use (Kamath et al., 2012; Li et al., 2016). Zuotai is primarily composed of $\beta$-HgS (metacinnabar) while cinnabar ( $Z$ hu Sha) is $\alpha$-HgS (Li et al., 2016; Wu et al., 2016). Only mercury sulfides are used in traditional remedies because they are considered to be safe at clinical dose levels (Liu et al., 2008). The Chinese Ministry of Health has closely monitored mercury contents in these medicines and publishes allowable doses (0.1-0.5 g/day) in the Pharmacopeia of China (Liang \& Shang, 2005; Liu et al., 2008). However, these doses can be considerably higher than what is considered to be safe in Western countries (Liu et al., 2008) (see Table S1). Inorganic mercury chloride $\left(\mathrm{HgCl}_{2}\right)$ and organic methylmercury $(\mathrm{MeHg})$ forms are highly toxic and never used in these treatments (Kamath et al., 2012). This distinction is important because it is the total mercury content rather than specific chemical forms that are commonly used to assess risk of traditional medicines, and this approach may be inaccurate.

Mercury is categorized as a nonessential metal with no biological function but concentration-dependent toxicity (Sfakianakis et al., 2015). Envrionmental transformation renders mercury of increased toxicologic relevance. First, the release of mercury vapor $\left(\mathrm{Hg}^{0}\right)$ occurs following evaporation from water, soil, volcanic eruption/ash, and following certain industrial practices such as pulp and paper production, metal mining, and coal, wood and peat burning (Morel, Kraepiel \& Amyot, 1998). Inorganic mercury is converted to $\mathrm{MeHg}$ by anaerobic bacteria present in sediments of fresh and ocean water (Liu, Goyer \& Waalkes, 2008). This step is key for methylation and eventual bioaccumulation (Morel, Kraepiel \& Amyot, 1998), affecting reactivity of mercury species as well as their concentration, lipid-permeability, and assimilation efficiency (Morel, Kraepiel \& Amyot, 1998; Klaassen, 2001). Biomagnfication of mercury occurs with consecutive passage up the food chain (Morel, Kraepiel \& Amyot, 1998; Authman et al., 2015). Because of their trophic positions as apex- or mesopredators, certain fish may contain high levels of mercury (Craig, 2003), and their consumption is the major route of human exposure to MeHg (Karimi, Fitzgerald $\&$ Fisher, 2012; Sheehan et al., 2014) (Table S1). In addition to the above dietary exposure, inorganic mercury exposure can occur via inhalation of mercury vapor from the chlor-alkali industry, heat extraction of gold from amalgam, and industrial discharge as $\mathrm{Hg}^{2+}$ ( $\mathrm{Liu}$, Goyer \& Waalkes, 2008). While this awareness has led to the use of various fish species to investigate toxicity of mercury, less attention has been given to developmental toxicity.

Fish tissues have a high bioaccumulation capacity and are sensitive indicators of mercury pollution. Ingested mercurials are bound, stored, and redistributed by the liver and can be retained for long periods (Raldúa et al., 2007; Authman et al., 2015). More recently, in laboratory model fish species, early life exposures to inorganic mercury and $\mathrm{MeHg}$ have resulted in deformities, with eye, tail, and finfold alterations (Samson \& Shenker, 2000). Advantages of these early life stage models are their low cost, rapid assessment, higher throughput, and easy determination of abnormalities. Medaka (Oryzias spp.) have been shown to be relatively sensitive to heavy metal exposure, including mercury (Dial, 1978; Ismail \& Yusof, 2011; Mu et al., 2011). Their wide salinity tolerance and the development of marine models have led to a variety of studies of metal toxicity (Inoue \& Takei, 2002; Chen et al., 2009; Mu et al., 2011). However, these studies have not tested traditional medicines (i.e., permutations of mercury ore, cinnabar). 
Japanese medaka (Oryzias latipes) is a freshwater aquarium model fish with transparent embryos that allow for evaluation in ovo (Iwamatsu, 2004) as well as having a variety of molecular tools available (Cheng et al., 2012). Measuring gene expression is useful in identifying treatment-induced changes and mechanisms of action following exposure (Fielden \& Zacharewski, 2001). Heme oxygenase-1 (Ho-1) is sensitive to a wide range of toxicants and has a protective role in the case of oxidative stress (Voelker et al., 2008; Weil et al., 2009). Metallothioneins (MT) are cysteine-rich, metal binding proteins that detoxify excess heavy metal ions and play a general role in antioxidant defense (Woo et al., 2006). Their expression has been shown to increase in a concentration-dependent manner in the presence of heavy metal contaminants; as such, they are considered to be a good biomarker for metal exposure in aquatic invertebrates (Amiard et al., 2006), laboratory model fish (Woo et al., 2006), and free-ranging populations of fish (Chan, 1995). These results follow closely with findings by Wu et al. (2016) in male Kunming mice exposed to organic-, inorganic mercury, and traditional medicines. The expression of these genes provides a way for us to evaluate mercury toxicity in medaka with the possibility of identifying mechanisms and commonalities with higher animal models. In this study, we determined the feasibility of using the medaka embryo assay as a tool to detect and compare developmental toxicity potentials of various forms of mercury ( $\alpha-\mathrm{HgS}, \beta-\mathrm{HgS}, \mathrm{HgCl}_{2}$, and $\mathrm{MeHg}$ ); we assessed them for mortality, morphological changes, and toxicity-related gene expression.

\section{MATERIALS AND METHODS}

\section{Mercury compounds}

$\mathrm{HgCl}_{2}, \mathrm{MeHg}$ (in the form of $\mathrm{CH}_{3} \mathrm{HgCl}$ ), and $\alpha-\mathrm{HgS}$ were obtained from Sigma-Aldrich (St. Louis, MO). Zuotai (hereafter referred to as $\beta$-HgS) was provided by the Northwest Institute of Plateau Biology, Chinese Academy of Sciences (Xining, China).

\section{Medaka culture and embryo collection}

Orange-red (OR) medaka (Oryzias latipes) were maintained at Duke University, Durham, NC, USA in an AHAB system (Pentair Aquatic Eco-Systems, Apopka, FL, USA) under standard recirculating water conditions. Brood stocks were housed in a charcoal-filtered, UV-treated water at $24 \pm 2{ }^{\circ} \mathrm{C}$ with $\mathrm{pH} 7.4$ and a light:dark cycle of 14:10 h. Dry food (Otohime $\beta 1$; Pentair Aquatic Eco-Systems) was fed three times per day with supplementation of Artemia nauplii (90\% GSL strain, Pentair Aquatic Eco-Systems) during the first two feedings. Embryos were collected by siphoning approximately $30 \mathrm{~min}$ after feeding, cleaned by rolling on a moistened paper towel, examined under a dissecting microscope (Nikon SMZ1500, Nikon Instruments, Inc., Melville, NY), and stage 10 embryos (6-7 h post fertilization (hpf)) were selected for experiments (Iwamatsu, 2004; Kinoshita et al., 2009) to represent an early exposure window (Villalobos et al., 2000; González-Doncel et al., 2008). Breeding colony maintenance, embryo collection, and experimental design followed animal care and maintenance protocols approved by the Duke University Institutional Animal Care and Use Committee (A062-15-02 and A031-15-01). 


\section{Experimental design}

The experiment was conducted over a 10-day interval, from early blastula (stage 10) to hatching (Iwamatsu, 2004). All mercury compounds were dissolved in DMSO and in addition $\alpha$-HgS and $\beta$-HgS were sonicated as described in Liu et al. (2008) and He, Traina $\&$ Weavers (2007) to increase solubility. Stocks were added to the wells of 6-well tissue culture plates (Corning, VWR International) at 1:1,000 dilutions in $5 \mathrm{~mL} 0.1 \%(\mathrm{w} / \mathrm{v})$ artificial seawater (ASW) to obtain final concentrations of 0 (Control), 0.001, 0.01, 0.1, 1, and $10 \mu \mathrm{M}$, with a final DMSO concentration in each $\leq 0.1 \%$. A total of $10-18$ embryos were placed in each well, with three wells per mercury compound concentration, and solutions were not renewed during the course of the experiment. DMSO controls were chosen based on previous studies showing it does not contribute to toxicity (e.g., Dong, Matsumura \& Kullman, 2010; Dong et al., 2014). Concentrations were chosen based on preliminary range finding assays in the same design that produced developmental abnormalities without leading to $100 \%$ mortality. Plates were incubated at $25 \pm 2{ }^{\circ} \mathrm{C}$ on a $14: 10 \mathrm{~h}$ light:dark cycle.

\section{Mortality, hatching, growth, and teratogenesis}

Embryos were observed daily under a dissecting microscope for mortality, hatching, delayed growth, and teratogenic effects. The latter included skeletal malformations, pericardial edema, decreased pigmentation of eyes, and swim bladder inflation or lack thereof. The Iwamatsu (2004) atlas was used to identify timing of events in organogenesis and hatching. Mortality was defined as any embryo with a brown, opaque chorion or any embryo with a non-beating heart. Hatching was defined as complete emergence from the chorion. Embryos that did not hatch by 10 days post fertilization (dpf) were considered dead. The experiment was terminated at $10 \mathrm{dpf}$ and fish were euthanized by an overdose of MS-222 (Dong, Matsumura \& Kullman, 2010; Colton et al., 2014).

\section{RNA extraction and real-time PCR}

A separate, identical exposure was run using the following concentrations: control, $\mathrm{MeHg}$ $(0.1 \mu \mathrm{M}), \mathrm{HgCl}_{2}(1 \mu \mathrm{M}), \alpha-\mathrm{HgS}(10 \mu \mathrm{M})$, and $\beta$-HgS $(10 \mu \mathrm{M})$. These were the highest concentrations of each compound that yielded sufficient embryo numbers for RT-PCR analysis ( $n=3,15$ embryos pooled per sample). Embryos were collected at 3 days post exposure, a time point selected based on survivorship in each treatment (Fig. 1). Embryos were homogenized with $1 \mathrm{ml}$ of RNAzol using a stainless steel Polytron homogenizer (Kinematica, Newark, NJ). Following homogenization, total RNA was isolated as described in Dong, Matsumura \& Kullman (2010). RNA quantity was determined using a NanoDrop ND-1000 spectrophotometer (ThermoScientific) and 260/280 ratios. Total RNA (500 ng) was reverse transcribed using High Capacity cDNA Reverse Transcription Kit (Applied Biosystems, Grand Island, NY). The following medaka specific RT-PCR primers were designed using Primer3 software and synthesized by Integrated DNA Technologies (Skokie, IL): Metallothionein (MT, AY466516, forward primer 5'-CTGCAAGAAAAGCTGCTGTG3', reverse primer 5'-GGTGGAAGTGCAGCAGATTC-3'); heme oxygenase-1 (Ho-1, AB163431, forward primer $5^{\prime}$-TGCACGGCCGAAACAATTTA-3', reverse primer $5^{\prime}$-AAAGTGCTGCAGTGTCACAG-3'), and $\beta$-actin (S74868, forward primer $5^{\prime}$ GAGTCCTGCGGTATCCATGA-3', reverse primer $5^{\prime}$-GTACCTCCAGACAGCACAGT$3^{\prime}$ ). The cDNA was amplified with SYBR Green PCR Master Mix (Applied Biosystems, 
A

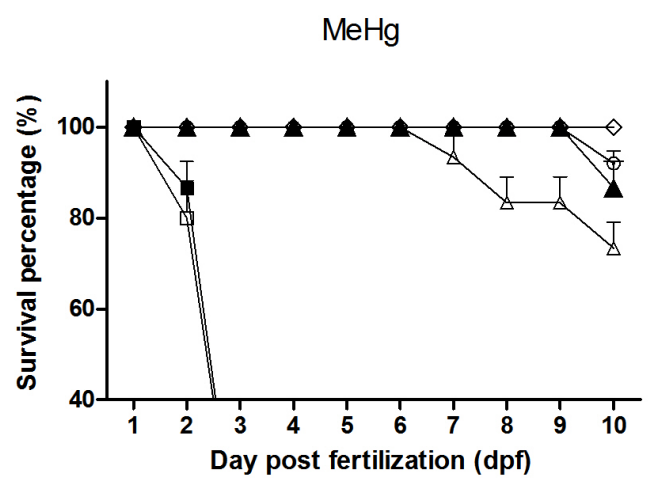

C

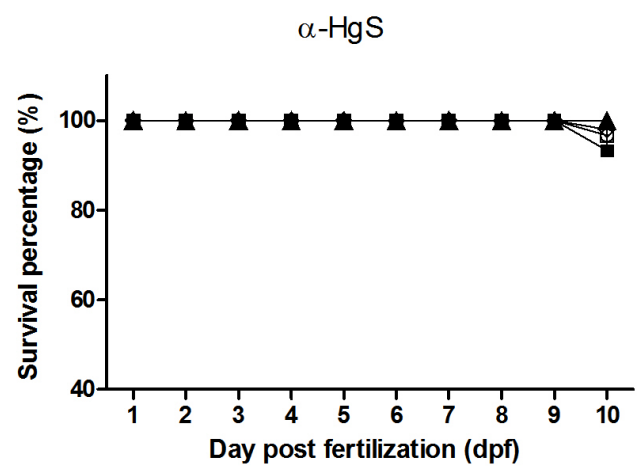

B

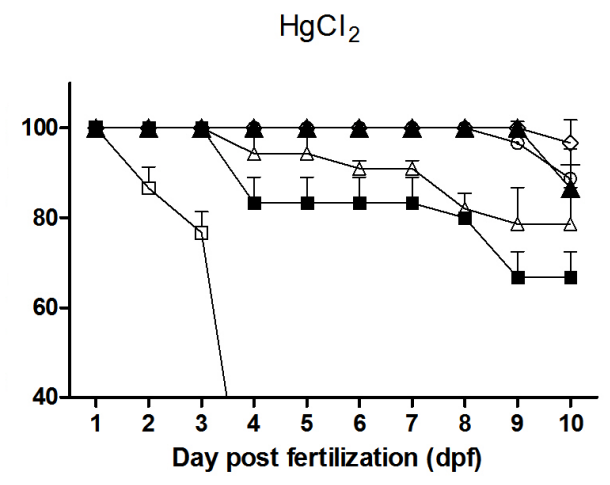

D

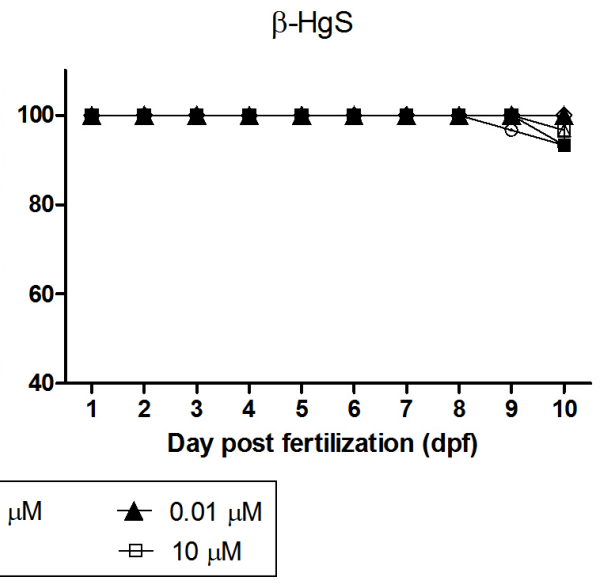

Figure 1 Survival (\%) of medaka embryos following exposure to $\mathrm{MeHg}(\mathrm{A}), \mathrm{HgCl}_{2}(\mathrm{~B}), \alpha-\mathrm{HgS}(\mathrm{C})$ and $\beta$-HgS (D) at 0 (control), $0.001,0.01,0.1,1$, or $10 \mu \mathrm{M}$ (from stage 10 to $10 \mathrm{dpf}$ ). Mortality was recorded daily as the percentage of nonviable individuals. Assays were run in triplicate with each data point representing the mean of $n=3$ replicates of $10-18$ embryos per replicate $( \pm \mathrm{SD})$.

Grand Island, NY). RT-PCR reaction conditions were $95^{\circ} \mathrm{C}$ for $15 \mathrm{~min}$ followed by 40 cycles of $95^{\circ} \mathrm{C}$ for $15 \mathrm{~s}$ and $60^{\circ} \mathrm{C}$ for $60 \mathrm{~s}$ on the Applied Biosystems $7900 \mathrm{HT}$ instrument using their Sequence Detection System 2.0 software. For each sample, the threshold cycle (Ct) was normalized with $\beta$-actin of the same sample according to Chen et al. (2004). The amplification was calculated using the $2^{-\Delta \Delta C T}$ method (Livak \& Schmittgen, 2001; Dong, Matsumura \& Kullman, 2010).

\section{Statistical analysis}

For each dpf, mean survival was calculated for each well and then used to calculate overall mean survival for each treatment group \pm SD. Survival data were arcsine-square root transformed for ANOVA. RT-PCR data were normalized to $\beta$-actin expression and presented as mean \pm SD. $\beta$-actin data were analyzed by a Grubbs Outlier test; outliers did not alter the results in subsequent tests and so were left in the analysis. For all measurements, one-way ANOVA followed by Tukey's post-hoc test was used to assess the statistical significance 
among groups. A $p \leq 0.05$ was considered to be statistically significant. All the data were analyzed using the SPSS 7.5 (SPSS Inc., Chicago, IL, USA).

\section{RESULTS}

\section{Mortality of medaka embryos after exposure to $\mathrm{Hg}$ compounds}

Embryos exposed to 1 or $10 \mu \mathrm{M} \mathrm{MeHg}$ did not survive to $3 \mathrm{dpf}$ (Fig. 1A). Whereas the mortality in these treatments was not statistically different from each other, they proved significantly higher than all other concentrations $(p<0.0001)$. The $0.1 \mu \mathrm{M}$ group had significantly higher mortality than controls by $10 \mathrm{dpf}(p<0.05)$, increasing to $16.7 \%$ and to $26.7 \%$ mortality by 7 - and $10 \mathrm{dpf}$, respectively (Fig. $1 \mathrm{~A}$ ). Those embryos exposed to 0.1 or $0.01 \mu \mathrm{M}$ concentrations had increased mortality versus the $0.001 \mu \mathrm{M}$ group $(p<0.05)$. While control mortality exceeded that of the $0.001 \mu \mathrm{M}$ group, this was due to the loss of a single control individual (Table $\mathrm{S} 2$ ). $\mathrm{HgCl}_{2}$, while toxic, proved less so than $\mathrm{MeHg}$. At $10 \mu \mathrm{M}$, all embryos died before $4 \mathrm{dpf}$. By $10 \mathrm{dpf}$, all other concentrations had $60 \%$ or higher survival, with all but the $10 \mu \mathrm{M}$ statistically the same as the control (Fig. 1B). In comparison with the above, $\alpha-\mathrm{HgS}$ and $\beta-\mathrm{HgS}$ were far less toxic and resembled survival levels seen in controls. For example, greater than $93 \%$ of embryos survived in all treatment groups by $10 \mathrm{dpf}$ (Figs. 1C-1D).

\section{Developmental toxicity}

At $5 \mathrm{dpf}$, embryos exposed to either $0.1 \mu \mathrm{M} \mathrm{MeHg}$ or $1 \mu \mathrm{M} \mathrm{HgCl}_{2}$ showed malformations (Fig. 2). Delayed or arrested growth was also observed in $5 \mathrm{dpf}$ embryos with $\mathrm{MeHg}$ and $\mathrm{HgCl}_{2}$ (Figs. 2B-2C). For example, $100 \%$ of individuals had reduced eye pigmentation, likely retina but further study is needed to confirm the site(s). By $10 \mathrm{dpf}, 100 \%$ of hatched $\mathrm{MeHg}$ and $\mathrm{HgCl}_{2}$ exposed individuals showed uninflated swim bladders (Figs. 2E-2F) and associated swimming alterations (i.e., loss of buoyancy and equilibrium), but not $\alpha-\mathrm{HgS}$ or $\beta$-HgS (Figs. 2G-2H). At $10 \mathrm{dpf}$, pericardial edema was observed in $80 \%$ of individuals in the $0.1 \mu \mathrm{M} \mathrm{MeHg}$ treatment but was absent in lower concentrations. This phenotype was also observed in $45 \%$ of the $1 \mu \mathrm{M} \mathrm{HgCl}_{2}$ exposed fish but was absent at lower concentrations. In severe cases, pericardial edema resulted in a tube heart in which expected anatomical positioning of heart chambers was absent (Figs. 2B-2C). No such edema was observed in $\alpha$-HgS and $\beta$-HgS treatments. At $10 \mathrm{dpf}$, we observed bent body axis, surficial edema involving the skin above the inner ear, and a single cell mass projecting from the dorsal skin (Fig. 2F). In general, MeHg was observed to cause more severe and higher rates of deformity. No developmental abnormalities occurred with exposure to $\alpha-\mathrm{HgS}$ or $\beta$-HgS by $5 \mathrm{dpf}$ (not shown in figures) or by $10 \mathrm{dpf}$ (Figs. 2G-2H).

\section{Metal toxicity-related gene expression}

$\mathrm{MeHg}$ and $\mathrm{HgCl}_{2}$ increased MT mRNA expression by 4 -fold and 5-fold over controls, respectively, while $\alpha$-HgS (1.4-fold) and $\beta$-HgS (1.30-fold) had no appreciable effects (Fig. $3 \mathrm{~A}$ ). $\mathrm{MeHg}$ and $\mathrm{HgCl}_{2}$ increased $\mathrm{Ho}-1 \mathrm{mRNA}$ expression by 6-fold and 2.3-fold over controls, respectively. $\alpha$-HgS significantly increased $\mathrm{Ho}-1$ expression (1.8-fold) over controls, but not to the degree of $\mathrm{MeHg}$ and $\mathrm{HgCl}_{2}$. $\beta$ - $\mathrm{HgS}$ had no significant effects (1.4-fold) (Fig. 3B). 


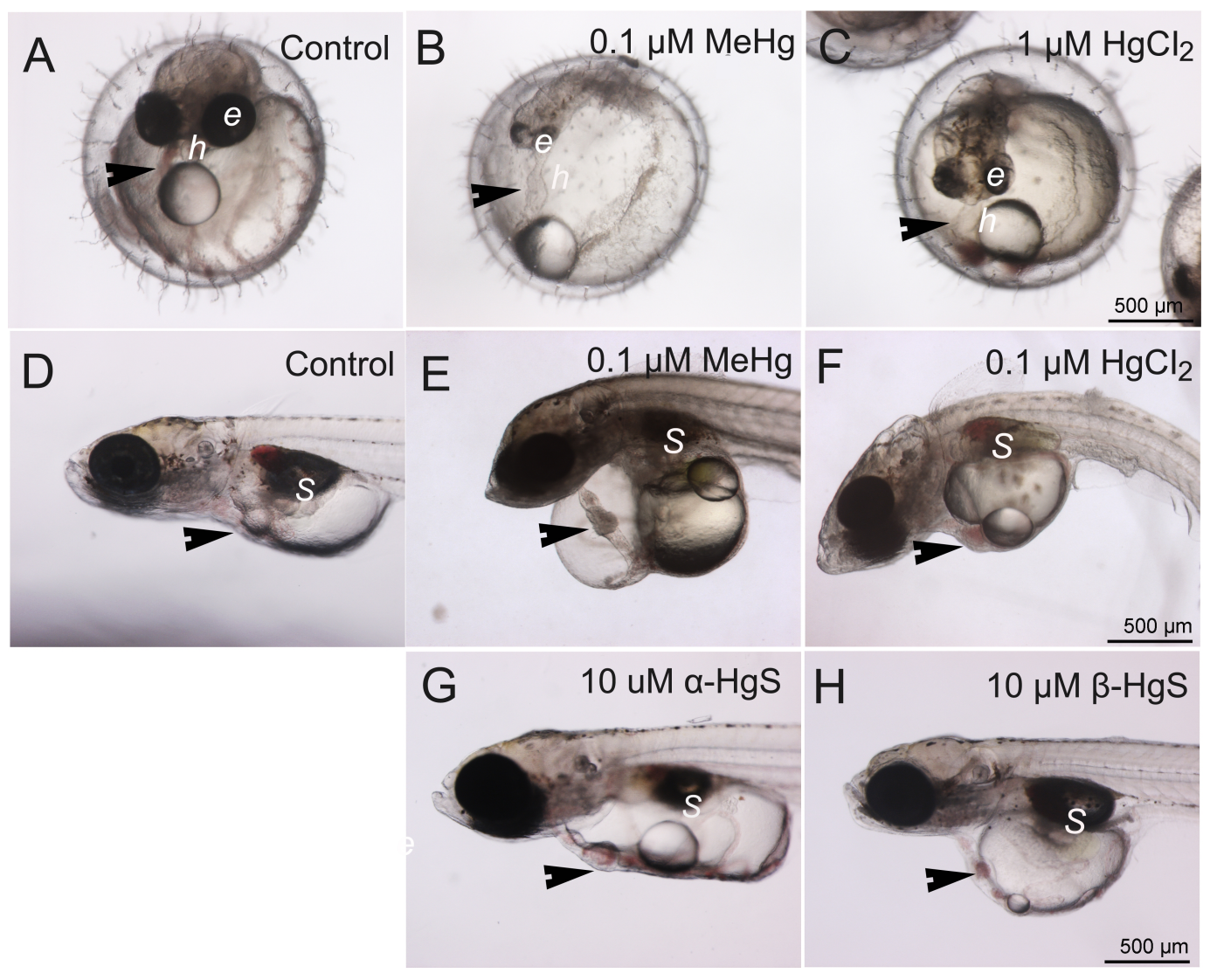

Figure 2 Control morphology and common phenotypic alterations in embryos and larvae following exposure to mercury compounds: embryos at $5 \mathrm{dpf}$ : (A) control; (B) $0.1 \mu \mathrm{M} \mathrm{MeHg}$; and (C) $1 \mu \mathrm{M}$ $\mathbf{H g C l}_{2}$. Larvae at $10 \mathrm{dpf}$ (D) control; (E) $0.1 \mu \mathrm{M} \mathrm{MeHg;} \mathrm{(F)} 1 \mu \mathrm{M} \mathrm{HgCl}_{2}$; (G) $10 \mu \mathrm{M} \alpha$-HgS; and (H) 10 $\mu \mathrm{M} \beta$-HgS. Arrows point to heart $(h) ; e$, eye; $S$, swim bladder. All images are at the same magnification, scale bar is $500 \mu \mathrm{m}$.

\section{DISCUSSION}

Mercury-based herbo-metallic preparations have been used in traditional medicines for thousands of years (Kamath et al., 2012) and continue to see usage today. Currently, the Pharmacopeia of China has 26 recipes that contain cinnabar $(\alpha-\mathrm{HgS})$. In Indian Ayurvedic medicine, Rasasindura, which is primarily composed of mercuric sulfides ( $\alpha$-HgS or $\beta$-HgS), is included in over 20 recipes (Kamath et al., 2012). In Tibetan medicine, Zuotai $(\beta-\mathrm{HgS})$ is included in a dozen popular remedies (Kan, 2013; Li et al., 2014). By comparing $\mathrm{MeHg}$ and $\mathrm{HgCl}_{2}$ to $\alpha-\mathrm{HgS}$ or $\beta$-HgS, we were able to assess compound related embryo toxicity and determine whether traditional medicines are toxicologically similar.

Numerous aquatic organisms have been studied with respect to the toxicity of mercury; however, most studies were focused on organic mercury (e.g., MeHg) (Liao et al., 2007; Cuello et al., 2012) and/or inorganic $\mathrm{HgCl}_{2}$ (Ismail \& Yusof, 2011; Wang et al., 2011; Wang et al., 2013). The toxic potential of $\alpha-\mathrm{HgS}$ and $\beta$-HgS used in traditional medicines is largely unknown. The present study demonstrated that embryo toxicity followed exposure 

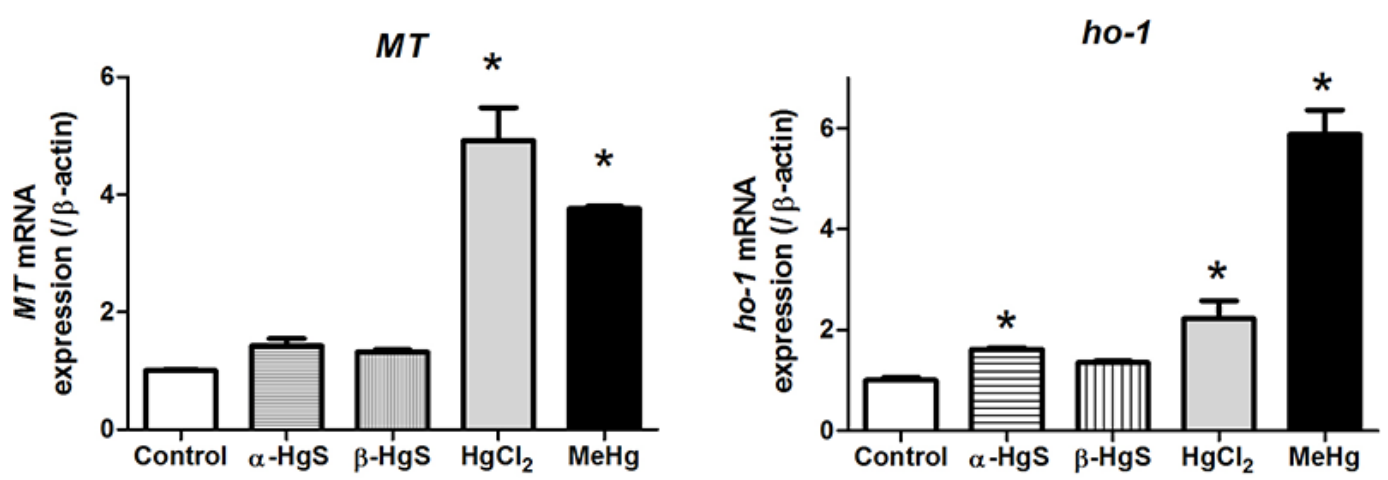

Figure 3 Analysis of gene expression in medaka embryos exposed to mercury compounds. Medaka embryos were sampled from control, $0.1 \mu \mathrm{M} \mathrm{MeHg}, 1 \mu \mathrm{M} \mathrm{HgCl} 2,10 \mu \mathrm{M} \alpha-\mathrm{HgS}$, and $10 \mu \mathrm{M} \beta$ - $\mathrm{HgS}$ treatment groups ( $n=3,15$ embryos pooled per replicate) at 3 days post-exposure. Total RNA was extracted and subjected to RT-PCR analysis for metallothionein (MT) and heme oxygenase-1 (Ho-1) gene expression using $\beta$-actin expression as the reference. Data are mean $\pm \mathrm{SD} .{ }^{\star}$ significantly different from controls with $p<0.05$.

to mercury, with $\mathrm{MeHg}$ the most toxic, followed by $\mathrm{HgCl}_{2}$, while $\alpha-\mathrm{HgS}$ and $\beta-\mathrm{HgS}$ had little toxicity.

In humans and rodents, $\mathrm{MeHg}$ is known to cross the placenta and reach the fetus where it is responsible for developmental toxicity (Clarkson, Magos \& Myers, 2003; Gandhi, Panchal \& Dhull, 2013). In laboratory studies using fish, MeHg exposure of early life stages produced developmental toxicity. Exposures of $\leq 80 \mathrm{ppm}\left(\mathrm{mg} \mathrm{L}^{-1}\right)$ to medaka embryos have increased mortality and caused teratogenic effects including stunted growth, decreased heart rate, and small eyes with reduced pigmentation, among others (Heisinger \& Green, 1975; Dial, 1978). In zebrafish (Danio rerio) larvae exposed to $\leq 25 \mathrm{mg} \mathrm{L}^{-1}$, down-regulation of $>70$ proteins was associated with morphological changes including but not limited to: smaller swim bladder, unabsorbed yolk, jaw deformities, and bent body axis (Cuello et al., 2012). In the present study, $0.1 \mu \mathrm{M} \mathrm{MeHg}$ produced pericardial edema that in severe cases formed a tube heart, reduced eye pigmentation, and failed swim bladder inflation. Each of these changes could impact the organism's health and survival (Dial, 1978; Hawryshyn, Mackay \& Nilsson, 1982; Marty, Hinton \& Cech, 1995).

Compared to $\mathrm{MeHg}, \mathrm{HgCl}_{2}$ primarily induces kidney and liver injury in rodents and fish (Klaassen, 2001; Lu et al., 2011a; Wu et al., 2016). However, exposure of mouse- (Van Maele-Fabry, Gofflot \& Picard, 1996), sea urchin- (Marc et al., 2002), and medaka embryos (Ismail \& Yusof, 2011) to $\mathrm{HgCl}_{2}$ produced developmental toxicity. Wang et al. (2011), Wang et al. (2013) and Wang et al. (2015) studied $\mathrm{HgCl}_{2}$ in adult marine medaka (Oryzias melastigma), and their proteomic analysis showed down-regulation of several dozen proteins including some related to oxidative stress after acute $(1,000 \mu \mathrm{g} / \mathrm{L}$ for $8 \mathrm{~h})$ and chronic (10 $\mu \mathrm{g} / \mathrm{L}$ for 60 days) exposures. Subsequent work on liver and brain developed a pathway analysis for potential toxicity (Wang et al., 2013; Wang et al., 2015). However, ultrastructural changes consistent with altered cells were more apparent in brain than in liver, where reported alterations of mitochondrial and endoplasmic reticulum were not supported by the figures. Wester \& Canton (1992) provided strong evidence for liver 
toxicity following exposure of adult guppies (Poecilia reticulata) to MeHg (1-10 $\mu \mathrm{g} / \mathrm{L}$ for $1 \& 3$ months). Alterations involved hepatocytes (cell swelling and nuclear pyknosis) and hyperplastic biliary epithelium of the intrahepatic bile duct.

We have shown that medaka have good potential as a model to investigate developmental effects of different forms of mercury. However, in this study, the potential for developmental toxicity of $\alpha-\mathrm{HgS}$ and $\beta$ - $\mathrm{HgS}$ proved much lower than that of $\mathrm{MeHg}$ or $\mathrm{HgCl}_{2}$. For example, at $10 \mathrm{dpf}$, less than $5 \%$ of medaka embryos died and survivors had no apparent teratogenic effects. These results are comparable with studies of $\alpha-\mathrm{HgS}$ and cinnabar-containing traditional medicines in mice (Lu et al., 2011a; Lu et al., 2011b; Wu et al., 2016) and rats (Shi et al., 2011). Similarly, $\beta$-HgS has been shown to be much less toxic as compared to $\mathrm{HgCl}_{2}$ in mice (Zhu et al., 2013; Li et al., 2016; Wu et al., 2016). In those studies, $\alpha-\mathrm{HgS}$ and $\beta$-HgS were administered orally at 1.5-6 fold (mouse studies) and 20 fold (rat study) above clinical doses, still fourfold higher than the Chinese Pharmacopoeia Allowable Limit (Shi et al., 2011). A recent study in mice showed that gestational exposure to low dose $\alpha-\mathrm{HgS}(10 \mathrm{mg} / \mathrm{kg} / \mathrm{day}$, p.o. $\times 4$ weeks) resulted in offspring with severe neurobehavioral dysfunctions (Huang et al., 2012).

The present study used aqueous exposure of embryonated eggs, which brings up bioavailability related to solubility and the role of the chorion. The solubility of cinnabar is known to be quite low $\left(<0.001 \mathrm{~g} / \mathrm{L}\right.$ at $\left.20{ }^{\circ} \mathrm{C}\right)$, but preparations described by Liu et al. (2008), used in the present study, can increase this value. However, future work will need to describe how formulation of the intended medicinal end product affects the solubility of this mineral (Kamath et al., 2012). The chorion, a semi-permeable membrane, provides a degree of protection from its surrounding environment (Villalobos et al., 2000) and, near time of hatching, becomes more permeable (Hamm \& Hinton, 2000). Because xenobiotics in general, and more recently nano-metals, have been shown to enter through chorion pore canals, this route can affect developing embryos (Villalobos et al., 2000; González-Doncel et al., 2003; Wu \& Zhou, 2012). Future work is needed to compare if and how different forms of mercury penetrate the chorion.

Mercury compounds display multiple organ toxicity (e.g., hepatotoxicity, nephrotoxicity and neurotoxicity) in adult humans and experimental animals (Klaassen, 2001; Liu, Goyer \& Waalkes, 2008; Lu et al., 2011b; Shi et al., 2011). One of the most common mechanisms for toxicity is oxidative stress. For example, mercury induces the production of reactive oxygen species (ROS) by binding to intracellular thiols (GSH and sulfhydryl proteins) and by acting as a catalyst in Fenton-type reactions, producing oxidative damage (Klaassen, 2001; Liu, Goyer \& Waalkes, 2008). Heme oxygenase-1 (Ho-1) is an oxidative stress biomarker and was one of the most sensitive genes in response to toxic stimuli in a study of zebrafish embryos acutely exposed to 14 different chemicals (Weil et al., 2009). In the present study, $\mathrm{MeHg}$ increased $\mathrm{Ho}-1$ by 6 -fold and $\mathrm{HgCl}_{2}$ by 2.3 -fold compared to controls, suggesting that $\mathrm{MeHg}$ produced more oxidative damage to embryos. The lack of increased Ho- 1 expression by $\alpha-\mathrm{HgS}$ and $\beta$-HgS coincided with the observed low developmental toxicity. This is in agreement with rodent studies that showed exposure to $\alpha-\mathrm{HgS}(300 \mathrm{mg} / \mathrm{kg})$ did not induce Ho-1 in liver or kidney, concordant with less hepato- (Lu et al., 2011a) and nephrotoxicity (Lu et al., 2011b). 
Metallothionein (MT) is thought to protect against oxidative stress and detoxify heavy metals including mercury (Klaassen, Liu \& Choudhuri, 1999). Induction of MT by mercury is a sensitive biomarker for exposure in a variety of fish species (Van CleefToedt, Kaplan \& Crivello, 2001; Cheung, Lam \& Chan, 2004; Chan et al., 2006; Oliveira et al., 2010), including Javanese medaka (Oryzias javanicus) (Woo et al., 2006). We found MT increased by 4-6 fold compared to controls with $\mathrm{MeHg}$ and $\mathrm{HgCl}_{2}$ exposure but were unchanged following $\alpha-\mathrm{HgS}$ and $\beta$-HgS. This is similar to rodent studies (Lu et al., 2011a; Shi et al., 2011). It is possible that the increases we observed were due to the timing of our sampling ( 3 day post exposure). That said, considerable development occurs over 3 days, including formation of many of the major organs (Iwamatsu, 2004). In zebrafish, $M T$ levels have been shown to have strong and ubiquitous expression during early embryonic development and drop off later, and it is highly susceptible to metals (Chen et al., 2004). The displacement of essential metals by $\mathrm{Hg}$ may compromise multiple cellular processes (Amiard et al., 2006), likely problematic during periods of rapid cell division and differentiation. At this point, we cannot directly link the morphological changes we observed to MT, but simply state that the observed increase was a response to the added mercury. The induction of MT by $\mathrm{MeHg}$ and $\mathrm{HgCl}_{2}$ reinforces the importance of this biomarker of mercury compounds in general, and identifies it as a potential biomarker for developmental toxicity. Future work with these compounds at intermediate concentrations may provide enough surviving embryos to gauge stage specific gene expression changes in response to various mercury compounds.

Overall, this study confirmed that the medaka embryo assay is a useful tool for determining and comparing potentials of developmental toxicity for various forms of mercury. We found survival even at middle concentrations of the more toxic forms, suggesting that our ranges were acceptable given the design of our study. We did not observe changes with $\alpha-\mathrm{HgS}$ and $\beta$-HgS, possibly due to the limitations in concentrations resulting from the initial constraint of comparing mercurials at the same concentrations. The rapidity, repeatability, broad salinity tolerance, and precision of this model will enable assessment of a broad range of formulations, concentrations, and mechanisms in the future.

\section{CONCLUSIONS}

The current study evaluated medaka embryo toxicity caused by exposure to $\mathrm{MeHg}$ and $\mathrm{HgCl}_{2}$ and compared results to mercuric sulfides ( $\alpha-\mathrm{HgS}$ and $\beta$ - $\left.\mathrm{HgS}\right)$ used in traditional medicines. $\mathrm{MeHg}$ and $\mathrm{HgCl}_{2}$ caused increased mortality and developmental toxicity. The latter presented as pericardial edema that, in severe cases, resulted in a tube heart, reduced eye pigmentation, and failure to inflate the swim bladder. Developmental toxicity appeared to be in the order of $\mathrm{MeHg}>\mathrm{HgCl}_{2} \gg \alpha-\mathrm{HgS}=\beta$ - $\mathrm{HgS}$, indicating that the chemical forms of mercury were a major determinant of its toxicity to medaka embryos. While this work only involved two medicinal formulations, these assays will be useful in the study of other permutations of cinnabar-based medicinals and their toxic mechanisms. 


\section{ADDITIONAL INFORMATION AND DECLARATIONS}

\section{Funding}

This study was supported by the National Natural Science Foundation of China (21267015, 81360508, 21567019); Natural Science Foundation of Inner Mongolia Autonomous Region of China (2015MS0804), the Project of Scientific and Technical Innovation of Inner Mongolia Autonomous Region (2015-2016) and Research Program of Science and Technology at the Universities of Inner Mongolia Autonomous Region (NJZY11202). The funders had no role in study design, data collection and analysis, decision to publish, or preparation of the manuscript.

\section{Grant Disclosures}

The following grant information was disclosed by the authors: The National Natural Science Foundation of China: 21267015, 81360508, 21567019. Natural Science Foundation of Inner Mongolia Autonomous Region of China: 2015MS0804.

Project of Scientific and Technical Innovation of Inner Mongolia Autonomous Region. Research Program of Science and Technology at Universities of Inner Mongolia Autonomous Region: NJZY11202.

\section{Competing Interests}

Jie Liu is an Academic Editor for PeerJ.

\section{Author Contributions}

- Wu Dong and Jie Liu conceived and designed the experiments, performed the experiments, analyzed the data, contributed reagents/materials/analysis tools, wrote the paper, prepared figures and/or tables, reviewed drafts of the paper.

- Lixin Wei conceived and designed the experiments, contributed reagents/materials/analysis tools, reviewed drafts of the paper.

- Yang Jingfeng analyzed the data, contributed reagents/materials/analysis tools, reviewed drafts of the paper.

- Melissa Chernick wrote the paper, prepared figures and/or tables, reviewed drafts of the paper.

- David E. Hinton contributed reagents/materials/analysis tools, wrote the paper, prepared figures and/or tables, reviewed drafts of the paper.

\section{Animal Ethics}

The following information was supplied relating to ethical approvals (i.e., approving body and any reference numbers):

Medaka (Oryzias latipes) were maintained at the Duke University Aquatic Research Facility under standard recirculating water conditions following approved animal care and maintenance protocols. Duke University Institutional Animal Care and Use Committee, No. A062-15-02 for breeding and No. A031-15-01 for toxicity testing protocol. 


\section{Data Availability}

The following information was supplied regarding data availability:

Figshare: https://figshare.com/s/23641deb4c3e10e09259;

https://figshare.com/s/3ef822119d859083275d;

https://figshare.com/s/7ae5a4e6a4cbfec828a6;

https://figshare.com/s/469c738bbda93b93873b;

https://figshare.com/s/60fad618f8beb67696b9;

https://figshare.com/s/ba2608b17e612ca244b7.

\section{Supplemental Information}

Supplemental information for this article can be found online at http://dx.doi.org/10.7717/ peerj.2282\#supplemental-information.

\section{REFERENCES}

Amiard JC, Amiard-Triquet C, Barka S, Pellerin J, Rainbow PS. 2006. Metallothioneins in aquatic invertebrates: their role in metal detoxification and their use as biomarkers. Aquatic Toxicology 76:160-202 DOI 10.1016/j.aquatox.2005.08.015.

Authman MMN, Zaki MS, Khallaf EA, Abbas HH. 2015. Use of fish as bio-indicator of the effects of heavy metals pollution. Journal of Aquaculture Research \& Development 6:328-340 DOI 10.4172/2155-9546.1000328.

Chan KM. 1995. Metallothionein: potential biomarker for monitoring heavy metal pollution in fish around Hong Kong. Marine Pollution Bulletin 31:411-415 DOI 10.1016/0025-326X(95)00125-7.

Chan KM, Ku LL, Chan PCY, Cheuk WK. 2006. Metallothionein gene expression in zebrafish embryo-larvae and ZFL cell-line exposed to heavy metal ions. Marine Environmental Research 62(Supplement 1):S83-S87 DOI 10.1016/j.marenvres.2006.04.012.

Chen W-Y, John JAC, Lin C-H, Lin H-F, Wu S-C, Lin C-H, Chang C-Y. 2004. Expression of metallothionein gene during embryonic and early larval development in zebrafish. Aquatic Toxicology 69:215-227 DOI 10.1016/j.aquatox.2004.05.004.

Chen XP, Li L, Wong CKC, Cheng SH. 2009. Rapid adaptation of molecular resources from zebrafish and medaka to develop an estuarine/marine model. Comparative Biochemistry and Physiology C-Toxicology \& Pharmacology 149:647-655 DOI 10.1016/j.cbpc.2009.01.009.

Chen C, Wu S, Wang Y, Hou J, Ma L, Sun X. 2012. Recent researches of synthetic mercury sulfide in traditional medicine system. Zhongguo Zhong Yao Za Zhi 37:2968-2970.

Cheng KC, Hinton DE, Mattingly CJ, Planchart A. 2012. Aquatic models, genomics and chemical risk management. Comparative Biochemistry and Physiology C-Toxicology \& Pharmacology 155:169-173 DOI 10.1016/j.cbpc.2011.06.009.

Cheung APL, Lam THJ, Chan KM. 2004. Regulation of Tilapia metallothionein gene expression by heavy metal ions. Marine Environmental Research 58:389-394 DOI 10.1016/j.marenvres.2004.03.084. 
Clarkson TW, Magos L, Myers GJ. 2003. The toxicology of mercury-current exposures and clinical manifestations. New England Journal of Medicine 349:1731-1737 DOI 10.1056/NEJMra022471.

Colton MD, Kwok KWH, Brandon JA, Warren IH, Ryde IT, Cooper EM, Hinton DE, Rittschof D, Meyer JN. 2014. Developmental toxicity and DNA damage from exposure to parking lot runoff retention pond samples in the Japanese medaka (Oryzias latipes). Marine Environmental Research 99:117-124 DOI 10.1016/j.marenvres.2014.04.007.

Craig PJ. 2003. Organometallic compounds in the environment. 2nd edition. Guildford: John Wiley \& Sons Ltd, p 415.

Cuello S, Ximenez-Embun P, Ruppen I, Schonthaler HB, Ashman K, Madrid Y, LuqueGarcia JL, Camara C. 2012. Analysis of protein expression in developmental toxicity induced by MeHg in zebrafish. Analyst 137:5302-5311 DOI 10.1039/c2an35913h.

Dial NA. 1978. Methylmercury: some effects on embryogenesis in the Japanese medaka, Oryzias latipes. Teratology 17:83-91 DOI 10.1002/tera.1420170116.

Dong W, Macaulay LJ, Kwok KWH, Hinton DE, Ferguson PL, Stapleton HM. 2014. The PBDE metabolite 6-OH-BDE 47 affects melanin pigmentation and THR $\beta$ MRNA expression in the eye of zebrafish embryos. Endocrine Disruptors 2:e969072 DOI 10.4161/23273739.2014.969072.

Dong W, Matsumura F, Kullman SW. 2010. TCDD induced pericardial edema and relative COX-2 expression in medaka (Oryzias latipes) embryos. Toxicological Sciences 118:213-223 DOI 10.1093/toxsci/kfq254.

Fielden MR, Zacharewski TR. 2001. Challenges and limitations of gene expression profiling in mechanistic and predictive toxicology. Toxicological Sciences 60:6-10 DOI 10.1093/toxsci/60.1.6.

Gandhi DN, Panchal GM, Dhull DK. 2013. Influence of gestational exposure on the effects of prenatal exposure to methyl mercury on postnatal development in rats. Central European Journal of Public Health 21:30-35.

González-Doncel M, Larrea M, Sánchez-Fortún S, Hinton DE. 2003. Influence of water hardening of the chorion on cadmium accumulation in medaka (Oryzias latipes) eggs. Chemosphere 52:75-83 DOI 10.1016/S0045-6535(03)00227-3.

González-Doncel M, Okihiro MS, Torija CF, Tarazona JV, Hinton DE. 2008. An artificial fertilization method with the Japanese medaka: implications in early life stage bioassays and solvent toxicity. Ecotoxicology and Environmental Safety 69:95-103 DOI 10.1016/j.ecoenv.2006.12.009.

Hamm JT, Hinton DE. 2000. The role of development and duration of exposure to the embryotoxicity of diazinon. Aquatic Toxicology 48:403-418

DOI 10.1016/S0166-445X(99)00065-X.

Hawryshyn CW, Mackay WC, Nilsson TH. 1982. Methyl mercury induced visual deficits in rainbow trout. Canadian Journal of Zoology 60:3127-3133 DOI 10.1139/z82-397.

He Z, Traina SJ, Weavers LK. 2007. Sonochemical dissolution of cinnabar ( $\alpha-\mathrm{HgS})$. Environmental Science \& Technology 41:773-778 DOI 10.1021/es0613299. 
Heisinger JF, Green W. 1975. Mercuric chloride uptake by eggs of the ricefish and resulting teratogenic effects. Bulletin of Environmental Contamination and Toxicology 14:665-673 DOI 10.1007/BF01685240.

Huang CF, Hsu CJ, Liu SH, Lin-Shiau SY. 2012. Exposure to low dose of cinnabar (a naturally occurring mercuric sulfide $(\mathrm{HgS})$ ) caused neurotoxicological effects in offspring mice. Journal of Biomedicine and Biotechnology 2012:Article 254582 DOI 10.1155/2012/254582.

Inoue K, Takei Y. 2002. Diverse adaptability in Oryzias species to high environmental salinity. Zoological Science 19:727-734 DOI 10.2108/zsj.19.727.

Ismail A, Yusof S. 2011. Effect of mercury and cadmium on early life stages of Java medaka (Oryzias javanicus): a potential tropical test fish. Marine Pollution Bulletin 63:347-349 DOI 10.1016/j.marpolbul.2011.02.014.

Iwamatsu T. 2004. Stages of normal development in the medaka Oryzias latipes. Mechanisms of Development 121:605-618 DOI 10.1016/j.mod.2004.03.012.

Kamath SU, Pemiah B, Sekar RK, Krishnaswamy S, Sethuraman S, Krishnan UM. 2012. Mercury-based traditional herbo-metallic preparations: a toxicological perspective. Archives of Toxicology 86:831-838 DOI 10.1007/s00204-012-0826-2.

Kan Z. 2013. An introduction of Zuotai in Tibetan patent medicine. Zhongguo Zhong Yao Za Zhi 38:1621-1623.

Karimi R, Fitzgerald TP, Fisher NS. 2012. A quantitative synthesis of mercury in commercial seafood and implications for exposure in the United States. Environmental Health Perspectives 120:1512-1519 DOI 10.1289/ehp.1205122.

Kinoshita M, Murata K, Naruse K, Tanaka M. 2009. Medaka: biology, management, and experimental protocols. Singapore: John Wiley \& Sons, Ltd.

Klaassen CD. 2001. Heavy metals and heavy-metal antagonists. In: Hardman JG, Limbird LE, Gilman AG, eds. The pharmacological basis of therapeutics. New York: McGraw-Hill, 1851-1876.

Klaassen CD, Liu J, Choudhuri S. 1999. Metallothionein: an intracellular protein to protect against cadmium toxicity. Annual Review of Pharmacology and Toxicology 39:267-294 DOI 10.1146/annurev.pharmtox.39.1.267.

Li H, Li W-K, Lu Y-F, Wei L-X, Liu J. 2016. The Tibetan medicine Zuotai influences clock gene expression in the liver of mice. PeerJ 4:e1632 DOI 10.7717/peerj.1632.

Li C, Wang D, Duo J, Duojie L, Chen X, Du Y, Yang H, Zheng Z, Yu M, Wei L. 2014. Study on safety of Tibetan medicine zuotai and preliminary study on clinical safety of its compound dangzuo. Zhongguo Zhong Yao Za Zhi 39:2573-2582.

Liang A, Shang M. 2005. General situation of the study on the toxicity of Cinnabaris. Zhongguo Zhong Yao Za Zhi 30:249-252.

Liao C-Y, Zhou Q-F, Fu J-J, Shi J-B, Yuan C-G, Jiang G-B. 2007. Interaction of methylmercury and selenium on the bioaccumulation and histopathology in medaka (Oryzias latipes). Environmental Toxicology 22:69-77 DOI 10.1002/tox.20236.

Liu J, Goyer RA, Waalkes MP. 2008. Toxic effects of metals. In: Klaassen CD, ed. Casarett \& Doull's toxicology: the basic science of poisons. New York: McGraw-Hill, 931-979. 
Liu J, Shi J-Z, Yu L-M, Goyer RA, Waalkes MP. 2008. Mercury in traditional medicines: is cinnabar toxicologically similar to common mercurials? Experimental Biology and Medicine 233:810-817 DOI 10.3181/0712-MR-336.

Livak KJ, Schmittgen TD. 2001. Analysis of relative gene expression data using real-time quantitative PCR and the 2- $\Delta \Delta$ CT method. Methods 25:402-408

DOI 10.1006/meth.2001.1262.

Lu Y-F, Wu Q, Liang S-X, Miao J-W, Shi J-S, Liu J. 2011a. Evaluation of hepatotoxicity potential of cinnabar-containing An-Gong-Niu-Huang Wan, a patent traditional Chinese medicine. Regulatory Toxicology and Pharmacology 60:206-211

DOI 10.1016/j.yrtph.2011.03.007.

Lu Y-F, Wu Q, Yan J-W, Shi J-Z, Liu J, Shi J-S. 2011b. Realgar, cinnabar and An-GongNiu-Huang Wan are much less chronically nephrotoxic than common arsenicals and mercurials. Experimental Biology and Medicine 236:233-239

DOI 10.1258/ebm.2010.010247.

Marc J, Maguer C, Bellé R, Mulner-lorillon O. 2002. Sharp dose- and time-dependent toxicity of mercuric chloride at the cellular level in sea urchin embryos. Archives of Toxicology Archiv für Toxikologie 76:388-391 DOI 10.1007/s00204-002-0368-0.

Marty GD, Hinton DE, Cech JJ. 1995. Oxygen consumption by larval Japanese medaka with inflated or uninflated swim bladders. Transactions of the American Fisheries Society 124:623-627 DOI 10.1577/1548-8659(1995)124<0623:NOCBLJ>2.3.CO;2.

Morel FMM, Kraepiel AML, Amyot M. 1998. The chemical cycle and bioaccumulation of mercury. Annual Review of Ecology and Systematics 29:543-566 DOI 10.1146/annurev.ecolsys.29.1.543.

Mu J, Wang Y, Wang X, Wang J. 2011. Toxic effects of cadmium, mercury, chromium and lead on the early life stage of marine medaka (Oryzias melastigma). Asian Journal of Ecotoxicology 6:352-360.

Oliveira M, Ahmad I, Maria VL, Serafim A, Bebianno MJ, Pacheco M, Santos MA. 2010. Hepatic metallothionein concentrations in the golden grey mullet (Liza aurata) relationship with environmental metal concentrations in a metal-contaminated coastal system in Portugal. Marine Environmental Research 69:227-233 DOI 10.1016/j.marenvres.2009.10.012.

Pharmacopeia of China. 2015. Pharmacopeia of the People's Republic of China. Pharmacopoeia Commission China: Chemical Industry Press.

Raldúa D, Díez S, Bayona JM, Barceló D. 2007. Mercury levels and liver pathology in feral fish living in the vicinity of a mercury cell chlor-alkali factory. Chemosphere 66:1217-1225 DOI 10.1016/j.chemosphere.2006.07.053.

Samson JC, Shenker J. 2000. The teratogenic effects of methylmercury on early development of the zebrafish, Danio rerio. Aquatic Toxicology 48:343-354 DOI 10.1016/S0166-445X(99)00044-2.

Sfakianakis DG, Renieri E, Kentouri M, Tsatsakis AM. 2015. Effect of heavy metals on fish larvae deformities: a review. Environmental Research 137:246-255

DOI 10.1016/j.envres.2014.12.014. 
Sheehan MC, Burke TA, Navas-Acien A, Breysse PN, McGready J, Fox MA. 2014. Global methylmercury exposure from seafood consumption and risk of developmental neurotoxicity: a systematic review. Bulletin of the World Health Organization 92:254-269F DOI 10.2471/BLT.12.116152.

Shi J-Z, Kang F, Wu Q, Lu Y-F, Liu J, Kang YJ. 2011. Nephrotoxicity of mercuric chloride, methylmercury and cinnabar-containing Zhu-Sha-An-Shen-Wan in rats. Toxicology Letters 200:194-200 DOI 10.1016/j.toxlet.2010.11.015.

Van Cleef-Toedt KA, Kaplan LAE, Crivello JF. 2001. Killifish metallothionein messenger RNA expression following temperature perturbation and cadmium exposure. Cell Stress \& Chaperones 6:351-359 DOI 10.1379/1466-1268(2001)006<0351:KMMREF>2.0.CO;2.

Van Maele-Fabry G, Gofflot F, Picard JJ. 1996. Defects in the development of branchial nerves and ganglia induced by in vitro exposure of mouse embryos to mercuric chloride. Teratology 53:10-20 DOI 10.1002/(SICI)1096-9926(199601)53:1<10::AID-TERA2>3.0.CO;2-D.

Villalobos SA, Hamm JT, Teh SJ, Hinton DE. 2000. Thiobencarb-induced embryotoxicity in medaka (Oryzias latipes): stage-specific toxicity and the protective role of chorion. Aquatic Toxicology 48:309-326 DOI 10.1016/S0166-445X(99)00032-6.

Voelker D, Stetefeld N, Schirmer K, Scholz S. 2008. The role of cypla and heme oxygenase 1 gene expression for the toxicity of 3,4-dichloroaniline in zebrafish (Danio rerio) embryos. Aquatic Toxicology 86:112-120 DOI 10.1016/j.aquatox.2007.10.007.

Wang Y, Wang D, Lin L, Wang M. 2015. Quantitative proteomic analysis reveals proteins involved in the neurotoxicity of marine medaka Oryzias melastigma chronically exposed to inorganic mercury. Chemosphere 119:1126-1133

DOI 10.1016/j.chemosphere.2014.09.053.

Wang M, Wang Y, Wang J, Lin L, Hong H, Wang D. 2011. Proteome profiles in medaka (Oryzias melastigma) liver and brain experimentally exposed to acute inorganic mercury. Aquatic Toxicology 103:129-139 DOI 10.1016/j.aquatox.2011.02.020.

Wang M, Wang Y, Zhang L, Wang J, Hong H, Wang D. 2013. Quantitative proteomic analysis reveals the mode-of-action for chronic mercury hepatotoxicity to marine medaka (Oryzias melastigma). Aquatic Toxicology 130-131:123-131.

Weil M, Scholz S, Zimmer M, Sacher F, Duis K. 2009. Gene expression analysis in zebrafish embryos: a potential approach to predict effect concentrations in the fish early life stage test. Environmental Toxicology and Chemistry 28:1970-1978 DOI 10.1897/08-627.1.

Wester PW, Canton HH. 1992. Histopathological effects in Poecilia reticulata (guppy) exposed to methyl mercury chloride. Toxicologic Pathology 20:81-92 DOI 10.1177/019262339202000110.

Woo S, Yum S, Jung JH, Shim WJ, Lee C-H, Lee T-K. 2006. Heavy metal-induced differential gene expression of metallothionein in Javanese Medaka, Oryzias javanicus. Marine Biotechnology 8:654-662 DOI 10.1007/s10126-006-6046-0.

Wu Q, Li W-K, Zhou Z-P, Li Y-Y, Xiong T-W, Du Y-Z, Wei L-X, Liu J. 2016. The Tibetan medicine Zuotai differs from $\mathrm{HgCl}_{2}$ and $\mathrm{MeHg}$ in producing liver injury in 
mice. Regulatory Toxicology and Pharmacology 78:1-7

DOI 10.1016/j.yrtph.2016.03.017.

Wu Y, Zhou Q. 2012. Dose- and time-related changes in aerobic metabolism, chorionic disruption, and oxidative stress in embryonic medaka (Oryzias latipes): underlying mechanisms for silver nanoparticle developmental toxicity. Aquatic Toxicology 124125:238-246 DOI 10.1016/j.aquatox.2012.08.009.

Zhu H, Wei L, Du Y, Wang D, Li C. 2013. The chronic toxicity study of Tibetan medicine Zuotai in mice. Shizheng Guoyi Guoyao 24:2022-2024. 